\title{
Apoptosis and necrosis: two different outcomes of cigarette smoke condensate-induced endothelial cell death
}

\author{
B Messner ${ }^{\star, 1}$, S Frotschnig ${ }^{2}$, A Steinacher-Nigisch ${ }^{1}$, B Winter ${ }^{1}$, E Eichmair ${ }^{1}$, J Gebetsberger $^{2,3}$, S Schwaiger ${ }^{4}$, C Ploner ${ }^{5}$, \\ G Laufer $^{1}$ and D Bernhard ${ }^{1}$
}

Cigarette smoking is one of the most important and preventable risk factors for atherosclerosis. However, because of the complex composition of cigarette smoke, the detailed pathophysiological mechanisms are not fully understood. Based on controversial reports on the pro-atherogenic activity of cigarette smoke condensate, also called tar fraction (CSC), we decided to analyse the effects of CSC on the viability of endothelial cells in vitro. The results of this study show that low concentrations of the hydrophobic tar fraction induces DNA damage resulting in a P53-dependent and BCL-XL-inhibitable death cascade. Western blot analyses showed that this cascade is caspase-independent and immunofluorescence analysis have shown that the apoptotic death signalling is mediated by the release of apoptosis-inducing factor. Higher CSC concentrations also induce apoptotic-like signalling but the signalling cascade is then redirected to necrosis. Despite the fact that CSC induces a profound increase in cellular reactive oxygen species production, antioxidants exhibit only a minimal cell death protective effect. Our data indicates that not only hydrophilic constituents of cigarette smoke extract, but also CSC is harmful to endothelial cells. The mode and the outcome of CSC-induced cell death signalling are highly concentration dependent: lower concentrations induce caspase-independent apoptosis-like cell death, whereas incubation with higher concentrations interrupts apoptotic signalling and induces necrosis. Cell Death and Disease (2012) 3, e424; doi:10.1038/cddis.2012.162; published online 15 November 2012

Subject Category: Experimental Medicine

Since the 1960s it is known that smoking is one of the major preventable risk factors for the development of atherosclerosis. ${ }^{1}$ In 2002, the World Health Organisation (WHO) predicted that by 2030 cigarette smoking caused deaths will increase up to eight million people per year worldwide. ${ }^{2}$ Epidemiological studies have underlined the strong impact of smoking on cardiovascular morbidity and mortality (e.g., 80\% increased risk for coronary artery diseases compared with non-smokers). In addition, clinical studies have shown that young smokers have a higher risk for an increased intima media thickness - an early step in the development of atherosclerosis. ${ }^{3}$ Despite this bulk of epidemiological and clinical data and based on the complex composition of cigarette smoke (cigarette smoke consists of $>4000$ different chemicals, which affects various inter- and intracellular biological processes), it is hardly surprising that the pathophysiological mechanisms are yet unknown. ${ }^{4}$

Typically, cigarette smoke is subdivided into two phases: the hydrophobic tar (cigarette smoke condensate, CSC) or particulate fraction, and the hydrophilic or gas phase (cigarette smoke extract, CSE). ${ }^{5}$ Pryor and Stone ${ }^{6}$ published that the hydrophilic phase contains nicotine, metals, a large number of oxidants and over $10^{15}$ short-lived free radicals/ puff, whereas the hydrophobic fraction comprises mainly carcinogenic chemicals and $>10^{17}$ long-lived free radicals/g.

As the clear definition of cell death endpoints is crucial for the pathophysiology of atherosclerosis (e.g., necrosisinduced inflammation) this project aims at investigating the effects of CSC on endothelial viability in vitro, focussing on the execution of CSC-induced cell death.

It is generally accepted that atherosclerosis is a multifactorial disease and many atherogenic processes lead to similar patho-biological effects. However, of these effects, endothelial cell death (and therefore endothelial dysfunction) takes a central role in atherogenesis. ${ }^{7,8}$ At the same time, the loss of endothelial cells has not only direct functional effects, but it is also crucial, which form of cell death is induced. Generally, cell death could be classified into two forms: apoptosis, also known as 'programmed cell death' and necrosis described as uncontrolled and accidental form of cell death. ${ }^{9,10}$ Apoptosis is an energy-dependent process characterised by cell shrinkage, nuclear condensation and fragmentation, as well as

\footnotetext{
${ }^{1}$ Cardiac Surgery Research Laboratory, Department of Surgery, Medical University of Vienna, Währinger Gürtel 18-20, Vienna 1090, Austria; ${ }^{2}$ Cardiac Surgery Research Laboratory, Department of Cardiac Surgery, Innsbruck Medical University, Innrain 66, Innsbruck A-6020, Austria; ${ }^{3}$ Division of Genomics and RNomics, Innsbruck Biocenter, Innsbruck Medical University, Fritz Pregel Street 3, Innsbruck 6020, Austria; ${ }^{4}$ Department of Pharmacognosy, Institute of Pharmacy, University of Innsbruck, Josef-Moeller-Haus, Innrain 52c, Innsbruck A-6020, Austria and ${ }^{5}$ Department of Operative Medicine, Plastic, Reconstructive and Aesthetic Surgery Innsbruck, Innsbruck Medical University, Anichstrasse 35, Innsbruck A-6020, Austria

*Corresponding author: B Messner, Cardiac Surgery Research Laboratories, Department of Surgery, Medical University of Vienna, AKH, Ebene 8 G09/07, Währinger Gürtel 18-20, Vienna A-1090, Austria. Tel: + 43140400 6949; Fax: + 43140400 6782; E-mail: Barbara.Messner@meduniwien.ac.at

Keywords: atherosclerosis; cigarette smoke condensate; apoptosis; necrosis; P53; BCL-XL

Abbrevations: CSC, cigarette smoke condensate; CSE, cigarette smoke extract; AIF, apoptosis inducing factor; LC3, microtubule associated protein light chain 3; LDH, lactate dehydrogenase; ATP, adenosine triphosphate; ROS, reactive oxygen species; 3-MA, 3-methyladenine; NAC, N-acetylcysteine; DHR, dihydrorhodamine Received 16.7.12; revised 28.8.12; accepted 04.9.12; Edited by A Stephanou
} 
cellular fragmentation into the so called apoptotic bodies, which are removed by phagocytic cells. Importantly, the most relevant difference of necrotic cell death compared to apoptosis is plasma membrane leakage and the resulting induction of inflammation in the affected tissue caused by the release of intracellular components. ${ }^{9,11}$

As apoptosis is essential in the development and homeostasis of organisms, this process is highly regulated and its induction depends on an array of different intracellular signals. ${ }^{12,13}$ One of the most important intracellular sensors for stress and damage signals (e.g., DNA damage) is the transcription factor $\mathrm{p53}$, which makes this protein the 'central safety guard' to prevent uncontrolled cell growth. ${ }^{14-16}$ P53 can initiate apoptosis by signalling towards mitochondria, and consequent induction of mitochondrial dysfunction: loss of membrane potential and mitochondrial outer membrane permeabilisation through activation of pro-apoptotic proteins of the Bcl-2 family. In contrast, anti-apoptotic proteins of the $\mathrm{Bcl}-2$ family (like $\mathrm{BCl}-\mathrm{XI}$ ) can inhibit mitochondrial membrane permeabilisation. ${ }^{17,18}$ During mitochondrial membrane permeabilisation, two major groups of pro-apoptotic proteins are released from the mitochondrial intermembrane space, determining the further signalling pathway. ${ }^{12,19}$ Release of cytochrome $c$ mediates the activation of a well-known group of proteases, the caspases. Caspases are a group of cysteine proteases, which are divided into initiator and effector caspases. If initiator caspases (e.g., caspase-9 within the apoptosome complex) are activated, they cleave and subsequently activate the downstream effector caspases (e.g., caspase-3). ${ }^{17,20,21}$

Alternatively, the release of other proteins induces a caspase-independent apoptotic signalling. Among them, one of the crucial effector proteins is apoptosis-inducing factor (AIF). ${ }^{12}$ In the course of caspase-independent apoptotic signalling, AIF translocates into the nucleus where it induces chromatin condensation and the formation of large chromatin fragments, but the detailed mechanism remains unclear until now. ${ }^{22,23}$

Over the last few years, two other types of programmed cell death were revealed: programmed necrosis and autophagy. The existence of a programmed necrosis is still controversially discussed as this form of cell death could only be demonstrated when apoptosis is inhibited. ${ }^{9,11}$ Zong et al. ${ }^{24}$ demonstrated that DNA damage actively initiates a programmed form of necrosis, which is independent of well-known apoptotic induction proteins like p53, Bax, Bak and caspases.

Also the classification of autophagy as an autonomous cell death mechanism is controversial. ${ }^{11}$ So far, autophagy is established as a survival mechanism of cells under nutrient deprivation by degradation and recycling of cellular components. Autophagic degradation of intracellular structures and organelles is induced by the formation of double-membrane vesicles (autophagosomes) and the hydrolytic degradation of cellular structures after fusion with lysosomes (autolysosomes). ${ }^{25}$ One prominent marker to study autophagy is LC3 (microtubule-associated protein light chain 3): conversion of LC3-I (cytoplasmatic form) to LC3-II (autophagosome-specific form) is an indicator for the induction of autophagy. ${ }^{26}$

Based on different in vitro and in vivo studies, the hydrophilic fraction of cigarette smoke is well known to contain pro-atherogenic compounds. Small hydrophilic components were shown to reach the circulation through the alveoli where they promote endothelial stress. ${ }^{27,28}$ The resulting endothelial dysfunction - as one of the first and critical steps in atherogenesis - is caused by CSE-induced endothelial cell contraction, ${ }^{27}$ the release of pro-inflammatory cytokines, ${ }^{27}$ catalalysation of oxidative reactions, ${ }^{29}$ the increased expression of adhesion molecules ${ }^{30}$ and finally the induction of endothelial cell death (resulting in endothelial denudation). ${ }^{31-33}$

Conflicting and a sparse number of data exist on the atherosclerosis-causing potential of the hydrophobic fraction. Penn et al. $^{34}$ stated that intramuscularly injection of concentrated cigarette tar does not promote atherosclerotic plaque formation in cockerels. Indeed, studies investigating the effect of CSC in vivo are rare. However, various in vitro experiments revealed CSC-induced cellular atherogenic alterations in endothelial cells as for instance: (a) genotoxic effects, ${ }^{35}$ (b) alteration in the cytokine expression, ${ }^{36}$ (c) upregulation of genes involved in matrix degradation, ${ }^{37}$ (d) CSC-induced adherence of monocytes to the endothelial cell monolayer, ${ }^{38}$ (e) CSC-induced surface expression of adhesion molecules on endothelial cells and transendothelial migration of monocytes $^{39}$ and (f) decreased migration ability of endothelial cells in vitro. ${ }^{40}$ All the mentioned processes are well known to be involved in atherogenesis initiation and may contribute to vascular dysfunction and the atherogenic process in vivo. However, only few data are published addressing the mode and signalling pathway of CSC-induced endothelial cell death in detail.

\section{Results}

CSC inhibits the proliferation and induces cell death in human umbilical vein endothelial cells. To examine the potential toxic effects of CSC on endothelial cells, we performed in vitro viability assays and tested for the induction of cell death by CSC. XTT-based analyses revealed that 50 and $100 \mu \mathrm{g} / \mathrm{ml}$ CSC reduce the number of viable cells significantly compared with the exponential growth of control cells (Figure 1a). Based on the fact that the XTT assay cannot differentiate between the inhibition of proliferation and the induction of cell death, we also directly tested for the induction of cell death by annexin V/propidium iodide staining by FACS analysis. Figure $1 \mathrm{~b}$ shows that CSC leads to an increase in the number of apoptotic and to a much lesser extent to an increase in necrotic cells. Another indicator of cell toxicity is the release of lactate dehydrogenase (LDH) through porous membranes. Analysis of LDH release from CSC-treated endothelial cells showed that incubation with $50 \mu \mathrm{g} / \mathrm{ml}$ CSC has no effect on membrane integrity, whereas incubation with $100 \mu \mathrm{g} / \mathrm{ml} \mathrm{CSC}$ induces a massive release of $\mathrm{LDH}$, which started after $48 \mathrm{~h}$ of incubation (Figure 1c; significant increase in extracellular LDH concentration of only $6.5 \%$ after $24 \mathrm{~h}$ is negligible). The contradictory observations between annexin V/propidium iodide staining and LDH assay was further explained by analysing the amount of DNA in treated cells. Figure 1e shows that treatment with $100 \mu \mathrm{g} / \mathrm{ml}$ CSC leads to the degradation of nuclear DNA in contrast to cells treated with $50 \mu \mathrm{g} / \mathrm{ml} \mathrm{CSC}$ and compared to control cells. Scanning electron microscopic analysis of endothelial 
a
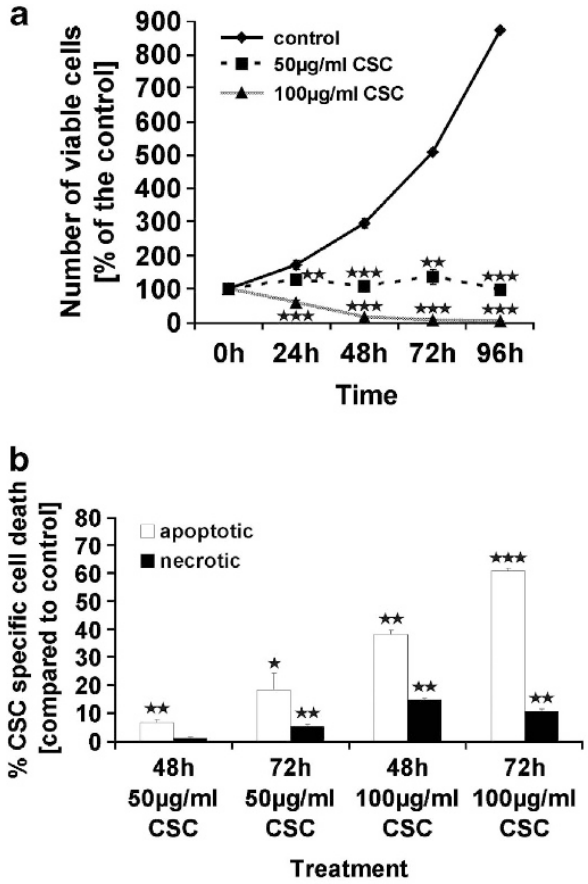

C

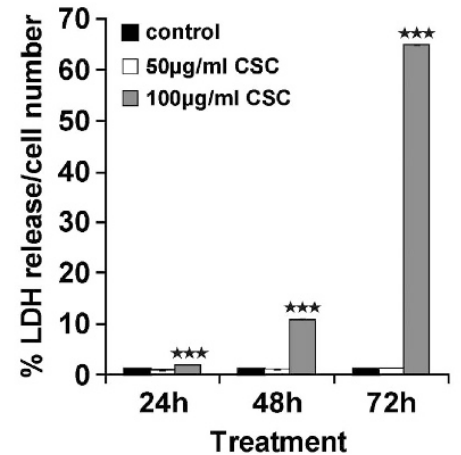

d
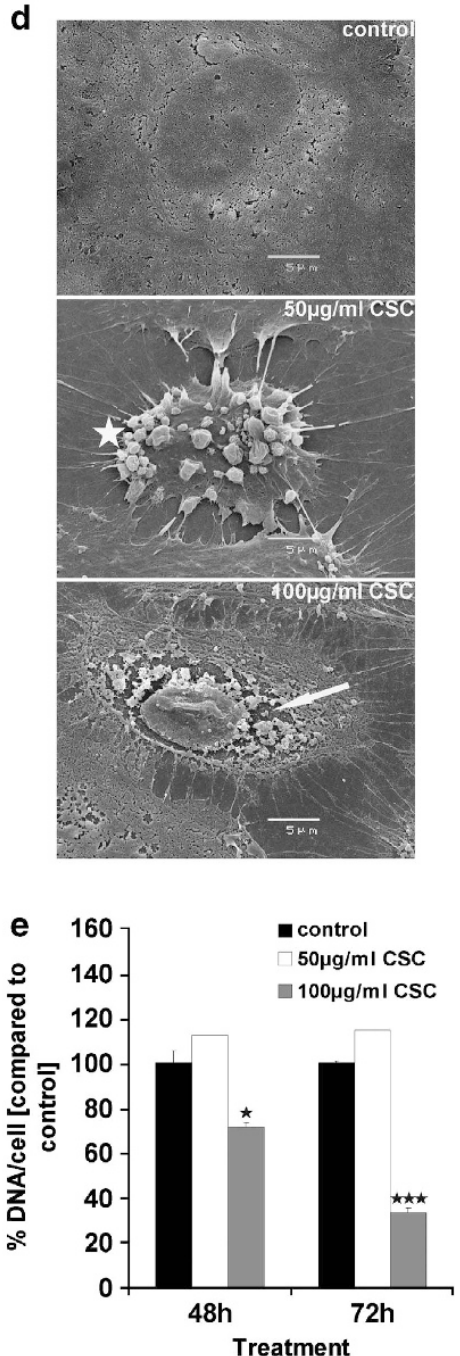

Figure 1 CSC inhibits proliferation and induces apoptotic and necrotic cell death. (a) Shows the effect of 50 and $100 \mu \mathrm{g} / \mathrm{ml} \mathrm{CSC} \mathrm{on} \mathrm{the} \mathrm{number} \mathrm{of} \mathrm{viable} \mathrm{endothelial} \mathrm{cells}$ in vitro determined by XTT assay. Mean values \pm S.D. of a representative experiment performed in quadruplicates are shown. (b) FACS analysis of CSC-induced cell death. Endothelial cells were incubated with 50 or $100 \mu \mathrm{g} / \mathrm{ml} \mathrm{CSC}$ for 48 and $72 \mathrm{~h}$. Apoptotic and necrotic cell death was detected by performing annexin V/propidium iodide stainings. (c) Endothelial cells were incubated with 50 or $100 \mu \mathrm{g} / \mathrm{ml} \mathrm{CSC} \mathrm{for} 24,48$ and $72 \mathrm{~h}$ before the LDH release was measured. Mean values \pm S.D. of a representative experiment performed in triplicates (annexin V staining) or quadruplicates (XTT assay and LDH assay) are shown. (d) Shows images of scanning electron microscopic analysis of control and CSC-treated endothelial cells (arrow: necrotic cell; star: apoptotic cell). Representative images are shown. (e) Shows data on the DNA content of HUVECs treated with $50 \mu \mathrm{g} / \mathrm{ml} \mathrm{CSC}$ and $100 \mu \mathrm{g} / \mathrm{ml}$ for the indicated times, respectively. The DNA content was analysed by FACS analysis. Asterisks indicate significant differences ( ${ }^{*} P<0.05$; $\left.{ }^{* \star} P<0.01 ;{ }^{* \star} P<0.001\right)$ compared with the corresponding controls

cells incubated with $50 \mu \mathrm{g} / \mathrm{ml}$ CSC showed characteristic features of apoptotic cell death: membrane blebbing and detachment (Figure 1d, star). Incubation with $100 \mu \mathrm{g} / \mathrm{ml} \mathrm{CSC}$ exhibits characteristic features of necrotic cell death: massive membrane disruption (see Figure 1d, arrow).

CSC causes DNA-strand breaks, induces P53 activation and affects the mitochondrial membrane potential. To test for the induction of DNA damage by CSC we performed Comet assays. Figure 2a shows that CSC (50 and $100 \mu \mathrm{g} / \mathrm{ml})$ increases the number of comet-positive cells already $6 \mathrm{~h}$ after CSC addition. It is already known that DNA damage leads to the stabilisation of the tumour-suppressor P53, and its activation, leading to pro-apoptotic signalling in affected cells. The involvement of P53 in CSC-induced cell death cascade was studied by western blot analyses. Figure $2 b$ shows that only the incubation with $50 \mu \mathrm{g} / \mathrm{ml} \mathrm{CSC}$ induces a temporary increase in P53 expression at $24 \mathrm{~h}$. However, after 48 and $72 \mathrm{~h}$ of CSC incubation with $50 \mu \mathrm{g} / \mathrm{ml}$ no induction and stabilisation of P53 was detectable. Incubation with higher CSC concentration $(100 \mu \mathrm{g} / \mathrm{ml})$ causes no P53 induction. The massive P53 protein degradation observed may be caused by necrosis-associated proteolytic processes. In conclusion, lower CSC concentrations activate the typical P53-dependent apoptotic death signalling pathway resulting in mitochondrial membrane depolarisation. JC-1-based analysis (see Figure $2 \mathrm{c}$ ) revealed that incubation with $50 \mu \mathrm{g} / \mathrm{ml}$ CSC induces a significant depolarisation of the mitochondria after $24 \mathrm{~h}$. Similarly, a higher CSC concentration $(100 \mu \mathrm{g} / \mathrm{ml})$ generates depolarised mitochondria already 


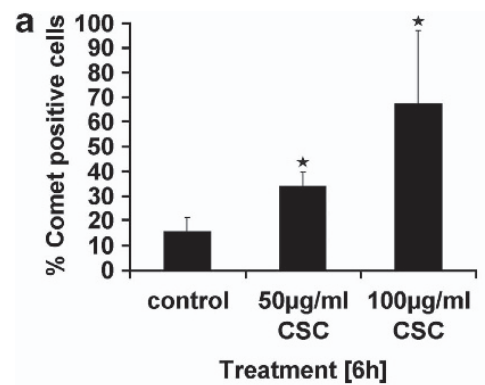

b

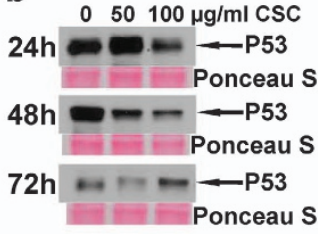

Treatment $[6 \mathrm{~h}]$
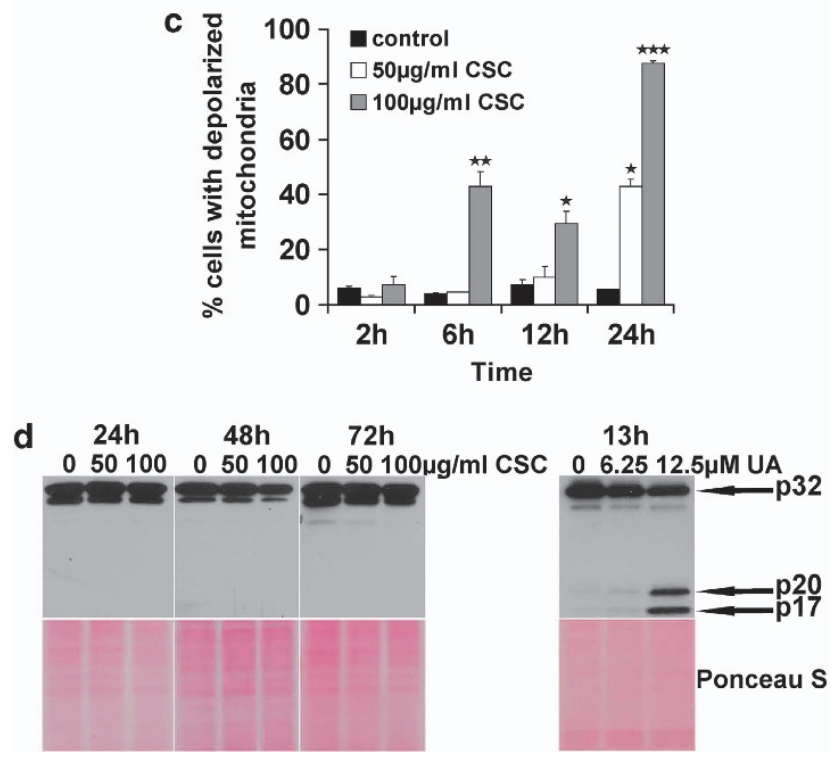

Figure 2 CSC-induced DNA damage and mitochondrial depolarisation without caspase-3 activation. (a) Shows data from a DNA damage analysis by the comet assay. Percent comet-positive cells compared with the control are shown. (b) Shows western blot analysis of P53 in HUVECs treated with 50 or $100 \mu \mathrm{g} / \mathrm{ml}$ CSC after 24, 48 and $72 \mathrm{~h}$, respectively. Representative blots are shown. Data in (c) shows JC-1-based FACS analysis of intracellular mitochondrial membrane potential after CSC treatment for 2, 6, 12 and $24 \mathrm{~h}$. Mean values \pm S.D. of a representative experiment performed in triplicates (JC-1 staining) or quadruplicates (Comet assay) are shown. (d) Shows western blot analysis of caspase-3 in CSC-treated endothelial cells. The cells were incubated with 50 or $100 \mu \mathrm{g} / \mathrm{ml} \mathrm{CSC}$ for 24,48 and $72 \mathrm{~h}$. The right western blot in (d) shows analysis of endothelial cells treated with ursolic acid ( 6.25 and $12.5 \mu \mathrm{M}$ for $13 \mathrm{~h}$ ), which serves as a positive control. Representative blots are shown. Mean values \pm S.D. are shown. Asterisks indicate significant differences ( $\left.{ }^{*} P<0.05 ;{ }^{* *} P<0.01 ;{ }^{* \star *} P<0.001\right)$ compared with the controls

after $6 \mathrm{~h}$ of incubation, importantly without the activation signal from P53.

As Csordas et al. ${ }^{41}$ previously suggested that energy depletion is characteristic for endothelial necrotic cell death, we also determined cellular ATP levels during CSC treatment. CSC decreased cellular energy levels until $6 \mathrm{~h}$ of incubation to $63 \%$ of the control (100 $\mu \mathrm{g} / \mathrm{ml} \mathrm{CSC})$. Impressively, this drop in cellular energy levels is followed by a dramatic increase in ATP up to $120 \%$ of the control $(100 \mu \mathrm{g} / \mathrm{ml} \mathrm{CSC})$ and $220 \%$ of the control ( $50 \mu \mathrm{g} / \mathrm{ml} \mathrm{CSC}$ ) after $24 \mathrm{~h}$, respectively - likely due to the fact that apoptotic cell death needs energy for the execution (see Supplementary Figure 6A).

As P53-activated death signalling is known to be mediated through caspase activation, we performed western blot analysis of caspase-3, an important effector caspase.
Figure $2 \mathrm{~d}$ displays that neither the incubation with $50 \mu \mathrm{g} / \mathrm{ml}$ CSC nor $100 \mu \mathrm{g} / \mathrm{ml}$ CSC induces the activation of caspase-3 over a time course from 24 to $72 \mathrm{~h}$. In addition, we performed a caspase-3 activity assay (see Supplementary Figure 6B). Endothelial cells were incubated with or without ursolic acid (UA) to obtain cytosolic extracts with active caspase-3. These extracts were then incubated with or without CSC and caspase activity was analysed. Supplementary Figure 6B shows that $50 \mu \mathrm{g} / \mathrm{ml}$ CSC is not only unable to induce caspase-3 activity but even significantly represses caspase-3 activity in cell-free extracts (see Supplementary Figure 6B).

Involvement of P53, BCL-XL, AIF and autophagy in CSCinduced cell death: differences between lower and high CSC concentrations. To further analyse the involvement of P53 and the anti-apoptotic mitochondrial protein BCL-XL in CSC-induced cell death, we infected endothelial cells with retroviruses containing a P53 shRNA vector and as P53activated death signalling is known to be mediated through pro-apoptotic BCL-2 family members we generated human umbilical vein endothelial cells (HUVECs) overexpressing the anti-apoptotic protein BCL-XL. P53 knock down cells were incubated with 50 and $100 \mu \mathrm{g} / \mathrm{ml} \mathrm{CSC}$. Figure $3 a$ shows that the knock down of P53 significantly inhibited CSC-induced cell death at low and high concentrations. Furthermore, the data in Figure $3 a$ shows that overexpression of $B C L-X L$ significantly represses CSC-induced cell death, both at lower $(50 \mu \mathrm{g} / \mathrm{ml})$ and higher concentrations $(100 \mu \mathrm{g} / \mathrm{ml})$.

To analyse the caspase-independent cell death signal downstream of the mitochondria, we performed immunofluorescence-based analysis of CSC incubated endothelial cells with anti-AIF antibody. The immunofluorescence analysis revealed that incubation with $50 \mu \mathrm{g} / \mathrm{ml} \mathrm{CSC}$ causes a change in the cellular AIF distribution from a more mitochondrial to a nuclear distribution - clearly visible after $72 \mathrm{~h}$ of CSC incubation (colocalisation of green AIF signal with blue nuclear staining; see Figure 3b). However, immunofluorescence staining of endothelial cells incubated with $100 \mu \mathrm{g} / \mathrm{ml}$ CSC showed no apoptosis-like translocation of AIF to the nucleus. Indeed, we were able to show that incubation of endothelial cells with $100 \mu \mathrm{g} / \mathrm{ml} \mathrm{CSC}$ induces the permeabilisation of lysosomes. The consequent release of enzymes may be central for the necrotic execution of cell death (e.g., plasma membrane permeabilisation). In addition, we also tested for autophagic signalling in CSC-treated endothelial cells as the lysosomes are central organelles in autophagic signalling. Therefore, we assessed the ratio of LC3-II per LC3-I. Figure $3 \mathrm{~d}$ shows that the ratio LC3-II/I increase significantly in response to the treatment with $100 \mu \mathrm{g} / \mathrm{ml} \mathrm{CSC}$. To further analyse the involvement of autophagy in CSC-induced cell death, we incubated endothelial cells with 3-methyladenine (3-MA) and analysed CSC-induced cell death. FACS-based analyses showed that inhibition of autophagosome formation by 3-MA was not able to inhibit CSC-induced cell death.

Cigarette smoke-induced oxidative stress is partially preventable by antioxidants. To test for the potential occurrence of oxidative stress, we performed DHR-123based analyses of oxidative stress. To do so, endothelial cells were incubated with different CSC concentrations as 
a

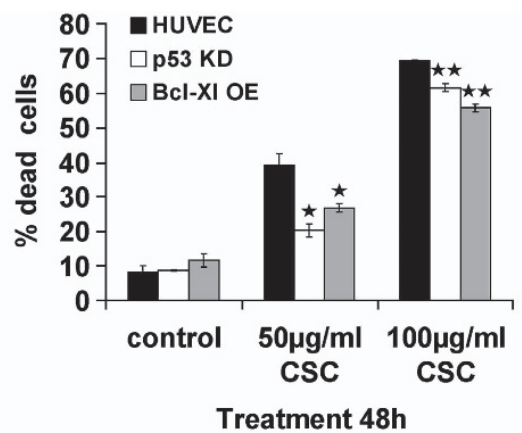

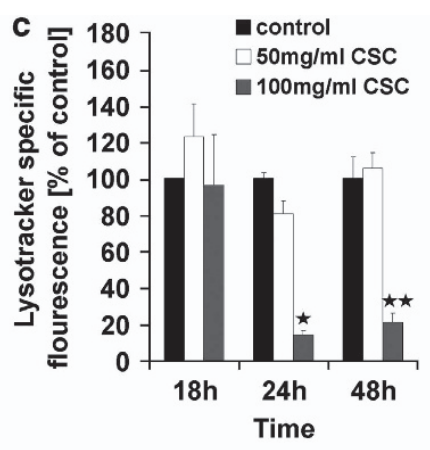

b contro $50 \mu \mathrm{g} / \mathrm{ml}$ CSC $100 \mu \mathrm{g} / \mathrm{ml}$ CSC Neg. control

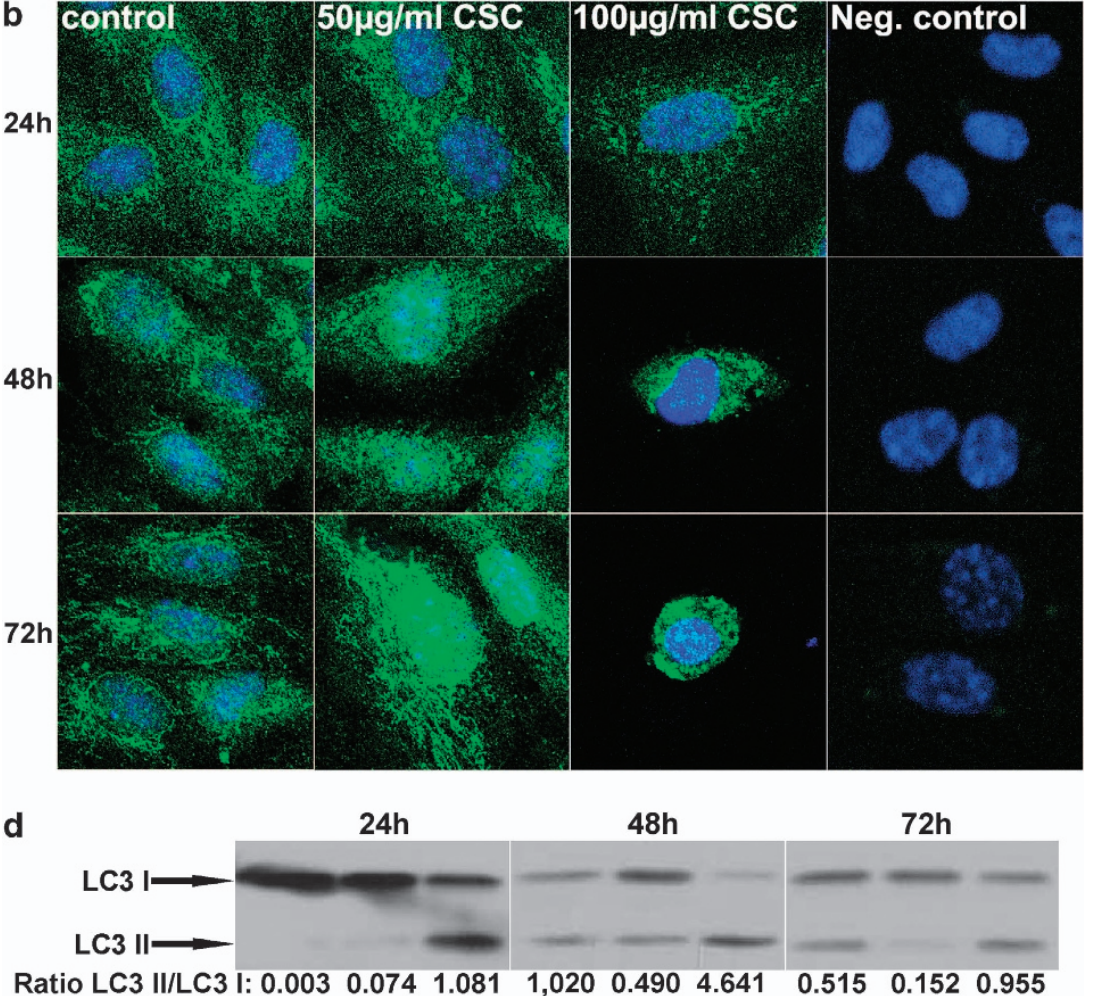

Figure 3 CSC-induced concentration-dependent signalling: translocation of AIF into the nucleus and permeabilisation of lysosomes. (a) Shows the result of annexin V/ propidium iodide staining and FACS analysis of CSC-treated P53 knock down and BCL-XL-overexpressing cells. The cells were incubated with 50 and $100 \mu \mathrm{g} / \mathrm{ml} \mathrm{CSC} \mathrm{for}$ $48 \mathrm{~h}$. (b) Shows immunofluorescence pictures of cellular AIF distribution in CSC-treated endothelial cells for 24, 48 and $72 \mathrm{~h}$. Green fluorescence is specific for AIF and the nucleus is stained with TOPRO-3 (shown in blue). (b) Shows also immunofluorescence pictures of endothelial cells (controls and CSC incubated cells) incubated with an isotype control (negative control; cells stained with FITC rabbit anti-human IgG isotype). (c) FACS-based analysis of lysosomal integrity. Endothelial cells were incubated with 50 or $100 \mu \mathrm{g} / \mathrm{ml} \mathrm{CSC}$ for 24,48 and $72 \mathrm{~h}$ and lysosomal integrity was analysed using the LysoTracker dye. (d) Shows western blot analysis of LC 3 (autophagy marker). HUVECs were incubated with 50 or $100 \mu \mathrm{g} / \mathrm{ml} \mathrm{CSC}$ for 24,48 and $72 \mathrm{~h}$. All experiments were performed in triplicates and were repeated at least three times. Mean values \pm S.D. are shown. Asterisks indicate significant differences $\left({ }^{\star} P<0.05 ;{ }^{* \star} P<0.01\right)$ compared with the controls. MFI $=$ mean fluorescence intensity

well as $1 \mathrm{mM} \mathrm{H}_{2} \mathrm{O}_{2}$ for $24 \mathrm{~h}$ (since $\mathrm{H}_{2} \mathrm{O}_{2}$ is a potent inducer of oxidative stress this incubation serves as positive control). Already after $5 \mathrm{~h}$ of incubation, we observed a significant and massive increase in the production of reactive oxygen species (ROS) with 50 and $100 \mu \mathrm{g} / \mathrm{ml}$ of CSC compared with the control and surprisingly also compared with $\mathrm{H}_{2} \mathrm{O}_{2}$, as it is a strong inducer of oxidative stress (Figure $4 \mathrm{a}$ ). In order to test for a potential ROS preventive effect of antioxidants (vitamin $\mathrm{E}$, vitamin $\mathrm{C}$ and $\mathrm{N}$-acetyl cysteine (NAC)), we pre-incubated endothelial cells with antioxidants and performed DHR-123-based analysis. Figure 4a shows that none of the above antioxidants was capable of preventing CSC-induced ROS formation in endothelial cells. In addition, FACS-based analyses of cell death revealed that neither vitamin C nor NAC were able to inhibit CSCinduced reduction in endothelial cell viability (Figure $4 \mathrm{~b}$ ). Only vitamin E was able to inhibit CSC-induced reduction in cell viability significantly $(100 \mu \mathrm{g} / \mathrm{ml}$ CSC for $48 \mathrm{~h})$, yet to a minor extent (increase in the amount of viable cells of $8 \%$ compared with CSC only treatment; see Figure 4b).

As P53 knock down and BCL-XL-overexpression were able to protect endothelial cells from CSC-induced cell death, we also analysed the effect of the constructs on 

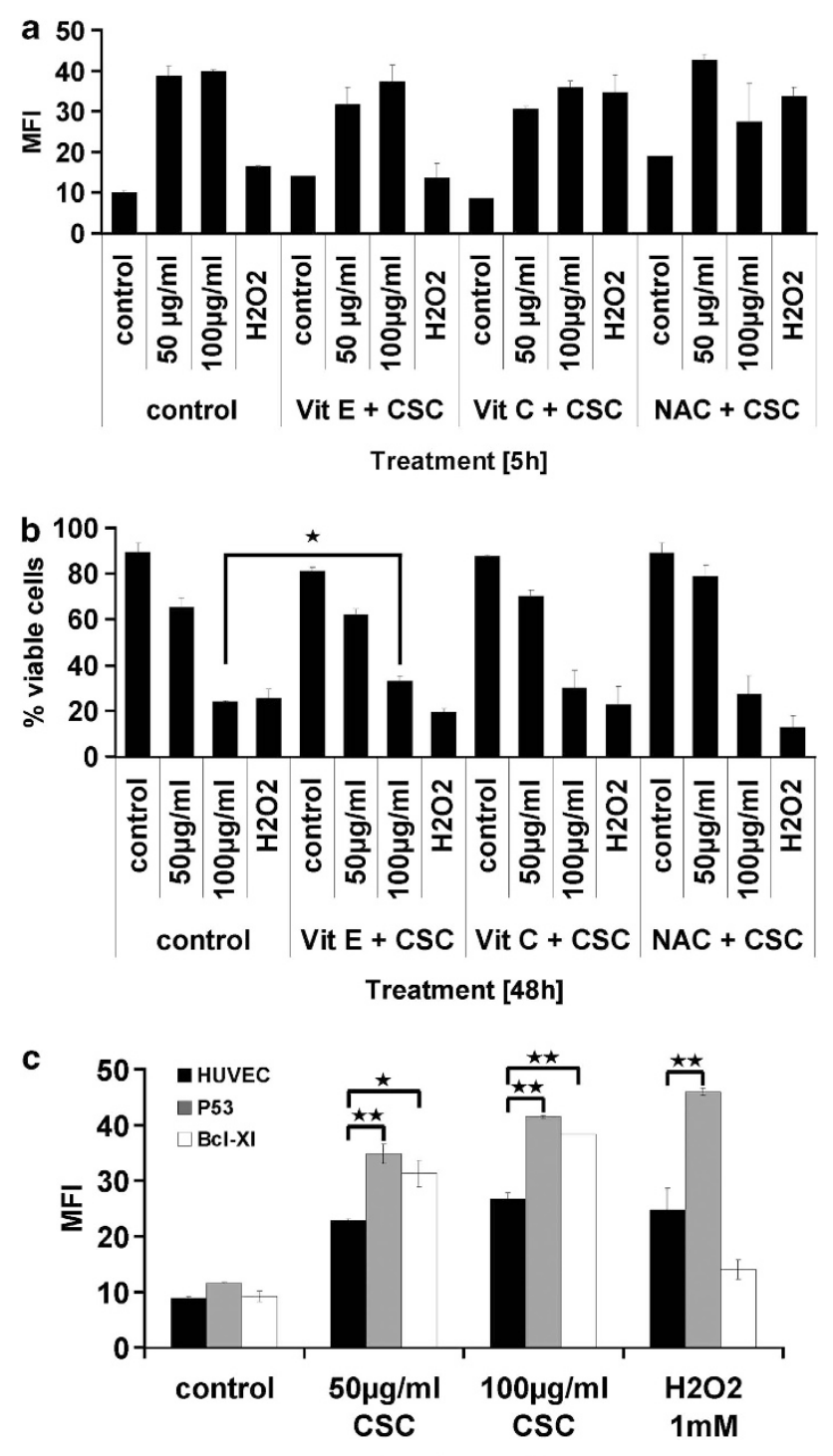

Treatment $5 \mathrm{~h}$

Figure 4 CSC-induced ROS production and the effect of antioxidants, P53 knock down and BCL-XL-overexpressing. (a) Shows the effect of CSC treatment on intracellular ROS production after $5 \mathrm{~h}$ of incubation. The effect of different antioxidants on CSC-induced ROS production was also analysed and is depicted in (a). To analyse the effect of different antioxidants on CSC-induced cell death FACS analysis were performed and the results are shown in (b). (c) Shows the effect of P53 knock down and BCL-XL-overexpression on CSC-induced ROS production. All experiments were performed in duplicates and were repeated at least three times. Mean values \pm S.D. are shown. Asterisks indicate significant differences $\left({ }^{\star} P<0.05\right.$; $\left.{ }^{* *} P<0.01\right)$ compared with the corresponding controls

CSC-induced ROS production. The results of FACS analysis in Figure 4c show that neither P53 knock down nor BCL-XL-overexpression prevented CSC treatment-induced endothelial ROS production.

\section{Discussion}

Various studies have been published demonstrating the contribution of CSE to atherogenesis in vitro and in vivo, whereas the data on the impact of the hydrophilic fraction are controversial. The aim of this study was to analyse the effect of CSC on the viability of endothelial cells in vitro with a special focus on the cell death outcome. As atherogenesis is generally considered to be an inflammatory process, the outcome of CSC-induced cell death is pathophysiologically highly relevant (concerning the pro-inflammatory activity of cells dying by necrotic mechanisms and therefore its atherosclerotic-causing potential).

Analysis of upstream signalling revealed that the triggering event in cell death induction - in apoptotic as well as programmed necrosis - is CSC-induced DNA-strand breaks. $^{42}$ Further analysis of DNA damage signalling demonstrates the causal role of P53 in low-dose CSC-induced endothelial cell death by showing an upregulation in P53 protein expression and the cell death protective activity of the P53 knock down. Treatment with higher CSC concentrations $(100 \mu \mathrm{g} / \mathrm{ml})$ had no effect on P53 protein expression, although the knock down of P53 shows a minimal protective effect (increase in viability compared with control cells of $8 \%$ ). Moreover, the involvement of the mitochondria in cell death signalling was examined. Analysis of the mitochondrial membrane potential has shown that CSC treatment induces a massive depolarisation. This depolarisation induces the loss in ATP synthesis. HPLC-based analysis of the ATP levels revealed that CSC induces an initial drop in cellular ATP levels followed by an increase in cellular ATP levels after $12 \mathrm{~h}$. This initial decrease in ATP levels could be explained by the energy consuming activation of survival processes - which were then switched off because of the CSC-induced cellular damage. Indeed, it is known that the apoptotic processes need ATP for cell death execution. So perhaps the massive increase in cellular ATP levels under low-dose CSC treatment (increase in ATP levels up to $222 \%$ ) is due to the necessity for energy to execute apoptotic cell death. ${ }^{43}$ However, exposure of endothelial cells to $100 \mu \mathrm{g} / \mathrm{ml} \mathrm{CSC}$ only induces a minimal increase in cellular ATP levels (increase in 18\% compared with the control). In contrast, such a high increase in cellular ATP levels is absent in cells incubated with $100 \mu \mathrm{g} / \mathrm{ml} \mathrm{CSC}$, possibly the reason for the occurrence of a necrotic endpoint in endothelial cells treated with higher CSC concentrations. The protective effect of BCL-XL-overexpression on CSCinduced cell death provides additional evidence for the involvement of the mitochondria in the apoptotic signalling at low- and high-dose exposure, respectively. Up to this event the only difference between low and high dosage-induced death signalling is the absence of P53 activation after treatment with $100 \mu \mathrm{g} / \mathrm{ml}$ CSC.

Crucial mediators in the classical apoptotic signalling pathways downstream of the mitochondria are caspases, which are activated on cleavage. Among caspases, caspase3 is a frequently activated enzyme. ${ }^{44}$ In CSC-treated HUVECs no caspase-3 activation/cleavage could be observed - neither at low nor at high CSC concentrations - and the in vitro activity assay even showed that caspase-3 activity is directly inhibited by CSC. One reason for the inhibited caspase activity could be the finding that CSC incubation induces a massive production of ROS and the fact that these cysteine proteases are highly redox sensitive. ${ }^{45}$ In summary, the above data suggest that CSC-induced apoptotic cell death signalling is blocked at the level of caspases. ${ }^{46}$ 
As we were able to show that apoptotic signalling in response to low-dose CSC causes a caspase-independent apoptotic signalling pathway, we analysed the cellular distribution of AIF as it is one prominent signalling molecule. $^{47,48}$ After $48 \mathrm{~h}$ of low-dose CSC treatment, a massive translocation of AIF to the nucleus could be observed. In contrast, treatment with $100 \mu \mathrm{g} / \mathrm{ml}$ CSC did not induce any change in cellular distribution.

Hence, one pivotal question remains: which proteins or organelles are involved in programmed necrosis in cells incubated with $100 \mu \mathrm{g} / \mathrm{ml}$ CSC after inhibition of the programmed cell death signal at the level of the mitochondria? The main executioner organelles for necrotic cell death are the lysosomes containing many proteases (e.g., cathepsins), lipases and DNAses (e.g., DNAse II), which are released to destroy cellular structures. ${ }^{49}$ Total lysosomal permeabilisation - as it is necessary for the induction of necrosis - is induced by different stimuli, for example, photodamage, sphingosine and ROS. ${ }^{50}$ Indeed, we were able to demonstrate that CSC induces a massive ROS production (see Figure 4 a) but it is unclear until now if the ROS-induced lysosomal permeabilisation is either an indirect signal through the mitochondria or a direct effect on the lysosomal membrane.

To analyse the role of ROS in the induction of CSCinduced cell death, we incubated the cell with well-known antioxidant scavenger molecules like vitamin $\mathrm{E}$, vitamin $\mathrm{C}$ and NAC. Surprisingly, these radical scavengers had neither a protective effect on the intracellular ROS production nor increases the viability of CSC-treated cells highly significant (only $8 \%$ increase in viability on treatment with $100 \mu \mathrm{g} / \mathrm{ml}$ CSC with vitamin E). Taken together, the data from the scavenger experiment it is unlikely that oxidative stress contributes to CSC-induced cell death. This hypothesis is supported by the finding that although P53 as well as BCL-XL-overexpression showed a significant protective effect on CSC-induced cell death, they exert no oxidative stress reducing activity. It is therefore speculated that CSC-induced endothelial cell death may be caused by non-oxidant DNA damage-causing agents in CSC, like polycyclic aromatic hydrocarbons. ${ }^{51}$

Beside these characteristic features of necrotic cell death in cells treated with $100 \mu \mathrm{g} / \mathrm{ml}$ CSC, we also detected autophagic signalling (conversion of LC3-I to LC3-II). This observation is not further surprising, as the occurrence of necrosis and autophagic signals in parallel could already be observed. , $^{911}$ Nevertheless, an autophagy inhibition experiment with 3-MA shows that autophagy is not crucial for CSC-induced cell death (statistically significant decrease in the amount of death cells of $6.5 \%$ is negligible). However, induction of autophagy signals could be seen as an attempt of the cell to produce ATP, either to survive or to induce apoptosis (to prevent necrosis-induced inflammation).

In summary, CSC-induced cell death is highly concentration dependent: lower CSC concentrations of $50 \mu \mathrm{g} / \mathrm{ml}$ induce apoptosis-like signalling whereas the apoptotic signalling in cells incubated with higher concentrations $(100 \mu \mathrm{g} / \mathrm{ml})$ is stopped at the level of the mitochondria and redirected to programmed necrosis. So, also higher CSC concentrations induces - in part - programmed cell death signals, suggested

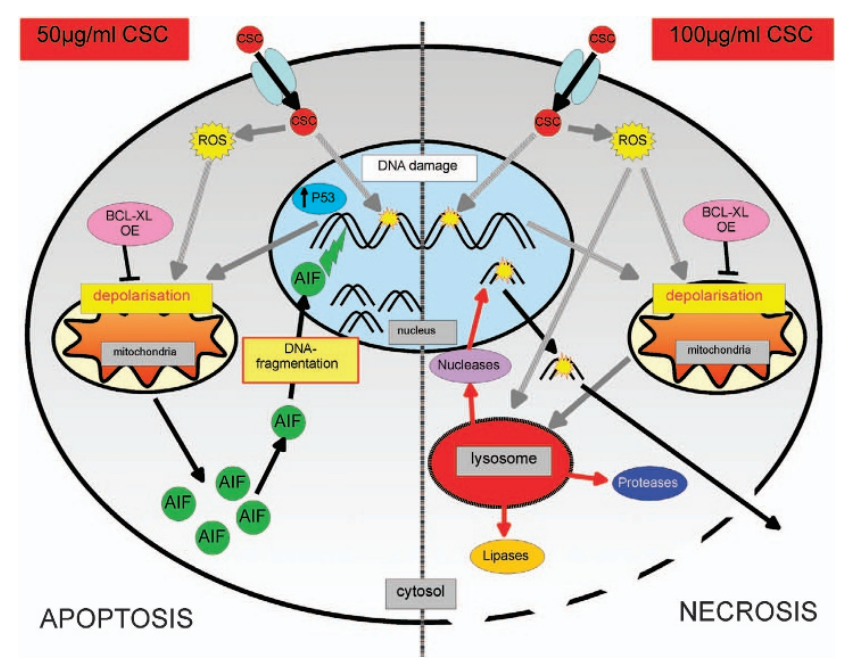

Figure 5 Schematic hypothetical sketch of CSC-induced cell death: signalling and execution of CSC-induced cell death. The schematic sketch is divided into two parts: the left side shows intracellular signalling after administration of $50 \mu \mathrm{g} / \mathrm{ml} \mathrm{CSC}$ and the right side the intracellular signalling after treatment with $100 \mu / \mathrm{ml}$ CSC. In all, $50 \mu \mathrm{g} / \mathrm{ml}$ induces apoptotic-like signalling in endothelial cells: CSC constituents enter the cells via unknown mechanisms and induce the formation of ROS (or are itself the source for ROS). CSC constituents (e.g., polycyclic aromatic hydrocarbon (PAH)) causes DNA damage and induces the activation of P53. The signal is then redirected from the P53 to the mitochondria and induces the depolarisation of mitochondrial membrane potential. This depolarisation could also be induced direct by ROS. CSC-induced mitochondrial depolarisation and rupture of the outer membrane induces the release of AIF, its translocation to the nucleus and the fragmentation of the DNA. In total, $100 \mu \mathrm{g} / \mathrm{ml}$ induces programmed necrosis signalling in endothelial cells: CSC constituents enter the cells via unknown mechanisms and induce the formation of ROS (or are itself the source for ROS). CSC constituents (e.g., PAH) causes DNA damage without the activation of P53. Depolarisation of mitochondrial membrane potential is induced either by DNA damage signalling without P53 contribution or direct by ROS. The next step in cell death signalling is the damage of lysosomes either induced via a signal from the mitochondria or via CSC-induced ROS formation. Damage of lysosomes induces the release of lipases and protease, which in turn induces plasma membrane rupture and the release of DNAses, finally leading to complete DNA degradation

by the cell death inhibitory activity of P53 knock down and BCL-XL-overexpression (see Figure 5).

Accordingly, the results from our study let us hypothesise that CSC could be responsible for two main steps in the atherogenic process: (i) CSC induces endothelial cell death and therefore it could be responsible for endothelial damage on the vessel wall and (ii) CSC triggers the initiation of an inflammatory response through induction of necrotic cell death. In conclusion, this in vitro-based work supplies a contribution to the understanding of smoking as a risk factor for atherosclerosis. As the in vivo concentration and the possible occurrence of metabolic modifications of CSC compounds in the blood are unknown, comparisons between the in vitro and in vivo situations are difficult to make. However, concerning the relative high concentrations of CSC in the mainstream smoke (up to $21.6 \mathrm{mg}$ per cigarette) it is quite possible that concentrations up to 50 and $100 \mu \mathrm{g} / \mathrm{ml} \mathrm{CSC}$ could be reached in the aortic wall, especially concerning the accumulation of smoke compounds in the aorta over a smoker's life. ${ }^{52}$ 


\section{Materials and Methods}

General. All reagents used were of purissimum or analytical grade quality and were purchased from Sigma-Aldrich (Sigma-Aldrich, Vienna, Austria) unless specified otherwise.

Cell isolation, culture and treatment. The isolation and culture of HUVECs has been described previously. ${ }^{53}$ The isolation and analysis of HUVECs was approved by the ethics committee of the Medical University of Vienna (No.: 1183/2012). Cells were routinely passaged in $0.2 \%$ gelatine-coated (Sigma, Steinheim, Germany) polysterene culture flasks (TPP, Trasadingen, Switzerland) in endothelial growth medium (Lonza, Anaheim, CA, USA) in a humidified atmosphere containing $5 \% \mathrm{CO}_{2}$. For cell death analyses, $3 \times 10^{5}$ HUVECs per well were seeded into gelatine-coated six-well plates (TPP). Before each experiment, medium was replaced by fresh medium. Cells were incubated with 50 and $100 \mu \mathrm{g} / \mathrm{ml} \mathrm{CSC}$ for the indicated times.

Preparation of CSC. The ethanol-soluble fraction of CS was isolated by solubilising the precipitated CSC from the cigarette smoke sampling device after preparation of CSE using ethanol. ${ }^{54}$ The mixture was then evaporated to dryness and solubilised in dimetyhlsulfoxide (Carl Roth $\mathrm{GmbH}$, Karlsruhe, Germany) to a final concentration of $100 \mathrm{mg} / \mathrm{ml}$. For the experiments, CSC was diluted in cell culture medium to the final indicated concentrations.

\section{Generation of lentiviral vectors}

$B C L-X L$ viruses. For constitutive overexpression of human BCL-XL in HUVECs, BCL-XL-encoding CDNA was PCR amplified and recombined into pDONR-207 (Invitrogen, Carlsbad, CA, USA) using Invitrogen's B/P recombination kit. A sequence verified clone was used for L/R recombination with pHR-SFFV-destIRES-Puro thereby generating the lentiviral expression plasmid pHR-BCL-XLIRES-Puro. P53 viruses: the lentiviral vector-encoding shRNA targeting human P53 was described elsewhere. ${ }^{55}$

\section{Generation of stable BCL-XL overexpressing and P53 knock- down HUVECs}

BCL-XL-overexpressing HUVECs. For lentiviral transduction, human HEK 293T cells were transiently transfected with lentiviral plasmids containing cDNAs coding for human BCL-XL or eGFP, along with the packaging plasmids PCMV 8.91 and pVSV-G (kindly provided by Didier Trono). At 48 and $72 \mathrm{~h}$ after transfection, lentiviral supernatant was sterile filtered $(0.2 \mu \mathrm{M})$, supplemented with polybrene to a final concentration of $4 \mu \mathrm{g} / \mathrm{ml}$ and added to the target cells overnight.

P53 knock down HUVECs. Viruses carrying P53 shRNAs were produced by transfecting 293T cells with corresponding pLVTHM constructs together with viral packaging vectors 5 (psPAX2 and pMD2G) by calcium phosphate transfection. P53 shRNA-containing viruses were harvested from the supernatant $48 \mathrm{~h}$ p.t. and applied to HUVEC cells for lentiviral infection in the presence of polybrene $(5 \mu \mathrm{g} / \mathrm{ml}) .{ }^{56,57}$

Quantification of cell death. For detection and/or quantification of cell death, forward/sideward light scattering analysis and annexin V/propidium iodide staining were used as described. ${ }^{58}$

Analysis of the number of viable cells. The number of viable cells in the cultures was determined using the XTT assay (Biomol, Hamburg, Germany) according to the manufacturer's instructions.

Lactate dehydrogenase release assay. The amount of LDH released from cells was quantified using the LDH cytotoxicity kit II (Biovision, Basel, Switzerland) according to the manufacturer's instructions.

Quantification of cellular DNA content. For the detection and quantification of nuclear DNA content, HUVECs were seeded into gelatine-coated six-well plates and allowed to adhere overnight. After replacing the medium with fresh medium, the cells were incubated with various CSC concentrations for the indicated times. After enzymatic detachment, the cells were washed, permeabilised with saponin $(1 \mathrm{mg} / \mathrm{ml})$, stained with propidium iodide $(50 \mu \mathrm{g} / \mathrm{ml})$ and analysed and quantified by flow cytometry using a Cytomics FC 500 (Beckmann Coulter, Brea, CA, USA).
Scanning electron microscopic analysis of cultured cells. Cells were grown on glass coverslips and treated as indicated. Thereafter, the cells were fixed by replacing the medium with $2.5 \%$ glutaraldehyde (in PBS). Following fixation, cells were dehydrated in a graded ethanol series $(70,90,100,100$, $100 \%$, and acetone), desiccated by critical point drying (Emitech K850; Quorum Technologies LTD, West Sussex, UK), mounted, sputtered with gold-palladium (Polaron CA 508; Fisons Instruments, Mainz-Kastel, Germany) and examined with a JEOL JSM - 5400 scanning electron microscope (Eching, Germany).

Western blotting. Western blotting was performed as previously described. ${ }^{59}$ Equal amounts of protein were loaded. Primary antibodies used were anticaspase-3 (monoclonal antibody to caspase-3; mouse; Alexis Biochemicals, Lausen, Switzerland), anti-P53 (P53; mouse; BD Pharmingen, Schwechat, Austria) and anti-LC3 antibody (rabbit anti-LC3; Sigma-Aldrich, Cat. No.: L8918). As a positive control for caspase-3 activation, we used endothelial cells treated with 6.25 and $12.5 \mu \mathrm{M} \mathrm{UA}$, respectively, as it is shown in Messner et al. ${ }^{60}$

Detection of changes in mitochondrial membrane potential. Cells were grown in gelatine-coated six-well plates and treated as indicated. After enzymatic detachment, the cells were washed and incubated with $5 \mu \mathrm{M} \mathrm{JC}-1$ (Molecular Probes, Vienna, Austria; Cat. No.: M34152) and subjected to FACS analysis using a Cytomics FC 500 (Beckmann Coulter).

Comet assay. To detect DNA-strand breaks, alkaline comet assays were performed according to the manufacturer's instruction (Trevigen Inc., Gaithersburg, MD, USA, comet assay HT; Cat. No. \#4252-040-K). Alkaline comet assay is a sensitive assay to detect DNA damage as it detects single- and double-stranded breaks. Endothelial cells were grown and exposed to 50 and $100 \mu \mathrm{g} / \mathrm{ml} \mathrm{CSC}$ for $6 \mathrm{~h}$, respectively. After treatment, the samples were handled as described in the manufacturer's instruction. Assay evaluation was performed by quantification of comet-positive cells (cells with comet tail/total cells).

Oxidant production. Oxidant production within HUVECs was assessed by measuring the oxidation of intracellular dihydrorhodamine 123 (DHR 123; SigmaAldrich, Munich, Germany), an oxidant-sensitive fluorochrome. Non-fluorescent dihydrorhodamine (DHR123) enters the cells, is transferred to the mitochondria and subsequently converted to fluorescent rhodamine 123 under oxidative conditions. The cells were treated with DHR $123(5 \mu \mathrm{M})$ followed by treatment with CSC. After CSC stimulation for the indicated times, the cells were trypsinised, collected and washed three times with PBS. DHR 123 oxidation was assessed by flow cytometry.

Staining of cells and fluorescence microscopy. To analyse the subcellular localisation of AIF, HUVECs were treated with CSC for the indicated times. After treatment, the cells were washed with PBS and fixed with 4\% PFA for $3 \mathrm{~min}$ at room temperature. Fixed cells were washed with PBS and permeabilised with $0.3 \%$ Triton $\mathrm{X}-100$ for $30 \mathrm{~min}$. Following an additional washing step with PBS, nonspecific binding sites were blocked with $1 \%$ bovine serum albumin (BSA) in PBS for $30 \mathrm{~min}$ at room temperature followed by staining with primary antibody against AIF (rabbit anti-AIF antibody, Cell Signaling, Danvers, MA, USA; Cat. No.: $4642 ; 0,4 \mu \mathrm{g} / \mathrm{ml}$ ) $\mathrm{O} / \mathrm{N}$ at $4^{\circ} \mathrm{C}$. After three washing steps with PBS, the cells were incubated with secondary antibody (Alexa Fluor 488, goat anti-rabbit, Invitrogen, Cat. No.: A11008) for $1 \mathrm{~h}$ in the dark and at room temperature. Thereafter, the monolayer was washed three times with PBS and nuclear staining was performed using Topro-3 (1:1000) for $10 \mathrm{~min}$ at room temperature in the dark. After three final washing steps, cells were mounted in ProLong Gold (Invitrogen) and analysed using a LSM 510 Meta attached to an Axioplan 2 imaging MOT using ZEN software (Zeiss, Oberkochen, Germany). As a negative control, CSC-treated endothelial cells were washed, fixed and permeabilised as the cells stained with the AIF antibody. After blocking with $1 \%$ BSA in PBS for 30 min at room temperature, the cells were stained with an isotype control antibody (direct FITCconjugated rabbit anti-human IgG-antibody, Antibodies Online Inc., Aachen, Germany; Cat. No.: ABIN101554; in the same concentration as the AIF-antibody).

Lysosomal labelling. For the staining of acidic compartments in HUVECs, LysoTracker green was used (Invitrogen, Molecular Probes, Vienna, Austria; Cat. No.: 1-7526). After CSC treatment of cells for the indicated times, HUVECs were stained with LysoTracker dye $(75 \mathrm{nM})$ for $30 \mathrm{~min}$ at $37^{\circ} \mathrm{C}$. The cells were then analysed using a LSM 510 Meta attached to an Axioplan 2 imaging MOT using ZEN software (Zeiss). 
Statistical analysis. Where indicated, primary data were tested for a Gaussian distribution and equality of variances. Further analyses were performed using $t$-Test.

\section{Conflict of Interest}

The authors declare no conflict of interest

Acknowledgements. This project was supported by the Austrian National Bank (Project \# 14590 to BM).

1. Mallat Z, Tedgui A. Apoptosis in the vasculature: mechanisms and functional importance. Br J Pharmacol 2000; 130: 947-962.

2. Organisation WH Tobacco - Fact Sheet No 339. World Health Organisation, 2012.

3. Knoflach M, Kiechl S, Kind M, Said M, Sief R, Gisinger M et al. Cardiovascular risk factors and atherosclerosis in young males: ARMY study (atherosclerosis risk-factors in male youngsters). Circulation 2003; 108: 1064-1069.

4. Powell JT. Vascular damage from smoking: disease mechanisms at the arterial wall. Vasc Med 1998; 3: 21-28

5. Ambrose JA, Barua RS. The pathophysiology of cigarette smoking and cardiovascular disease: an update. J Am Coll Cardiol 2004; 43: 1731-1737.

6. Pryor WA, Stone K. Oxidants in cigarette smoke. Radicals, hydrogen peroxide, peroxynitrate, and peroxynitrite. Ann NY Acad Sci 1993; 686: 12-27; discussion 27-28

7. Mannarino E, Pirro M. Molecular biology of atherosclerosis. Clin Cases Miner Bone Metab 2008; 5: 57-62.

8. Zheng Y, Gardner SE, Clarke MC. Cell death, damage-associated molecular patterns, and sterile inflammation in cardiovascular disease. Arterioscler Thromb Vasc Biol 2011; 31 2781-2786.

9. Edinger AL, Thompson CB. Death by design: apoptosis, necrosis and autophagy. Curr Opin Cell Biol 2004; 16: 663-669.

10. Kanduc D, Mittelman A, Serpico R, Sinigaglia E, Sinha AA, Natale $C$ et al. Cell death: apoptosis versus necrosis (review). Int J Oncol 2002; 21: 165-170.

11. Duprez L, Wirawan $E$, Vanden Berghe $T$, Vandenabeele $P$. Major cell death pathways at a glance. Microbes Infect 2009; 11: 1050-1062.

12. Elmore S. Apoptosis: a review of programmed cell death. Toxicol Pathol 2007; 35 495-516.

13. Strasser A, O'Connor L, Dixit VM. Apoptosis signaling. Annu Rev Biochem 2000; 69 217-245.

14. Vogelstein B, Lane D, Levine AJ. Surfing the p53 network. Nature 2000; 408 : 307-310.

15. Haupt S, Berger M, Goldberg Z, Haupt Y. Apoptosis - the p53 network. J Cell Sci 2003; 116(Part 20): 4077-4085.

16. Chipuk JE, Green DR. Dissecting p53-dependent apoptosis. Cell Death Differ 2006; 13 994-1002.

17. van Loo G, Saelens X, van Gurp M, MacFarlane M, Martin SJ, Vandenabeele P. The role of mitochondrial factors in apoptosis: a Russian roulette with more than one bullet. Cell Death Differ 2002; 9: 1031-1042.

18. Larsen CJ. [The BCL2 gene, prototype of a gene family that controls programmed cell death (apoptosis)]. Ann Genet 1994; 37: 121-134.

19. Green DR, Reed JC. Mitochondria and apoptosis. Science 1998; 281: 1309-1312.

20. Crawford ED, Wells JA. Caspase substrates and cellular remodeling. Annu Rev Biochem 2011; 80: 1055-1087.

21. Shi Y. Mechanisms of caspase activation and inhibition during apoptosis. Mol Cell 2002; 9 459-470.

22. Cande $\mathrm{C}$, Cecconi F, Dessen $\mathrm{P}$, Kroemer G. Apoptosis-inducing factor (AIF): key to the conserved caspase-independent pathways of cell death? J Cell Sci 2002; 115(Part 24) 4727-4734.

23. Lorenzo HK, Susin SA, Penninger J, Kroemer G. Apoptosis inducing factor (AIF): a phylogenetically old, caspase-independent effector of cell death. Cell Death Differ 1999; 6 : 516-524.

24. Zong WX, Ditsworth D, Bauer DE, Wang ZQ, Thompson CB. Alkylating DNA damage stimulates a regulated form of necrotic cell death. Genes Dev 2004; 18: 1272-1282.

25. Mizushima N, Ohsumi Y, Yoshimori T. Autophagosome formation in mammalian cells. Cell Struct Funct 2002; 27: 421-429.

26. He C, Klionsky DJ. Regulation mechanisms and signaling pathways of autophagy. Annu Rev Genet 2009; 43: 67-93

27. Bernhard D, Csordas A, Henderson B, Rossmann A, Kind M, Wick G. Cigarette smoke metal-catalyzed protein oxidation leads to vascular endothelial cell contraction by depolymerization of microtubules. FASEB J 2005; 19: 1096-1107.

28. Henderson B, Csordas A, Backovic A, Kind M, Bernhard D, Wick G. Cigarette smoke is an endothelial stressor and leads to cell cycle arrest. Atherosclerosis 2008; 201: 298-305.
29. Edirisinghe I, Arunachalam G, Wong C, Yao H, Rahman A, Phipps RP et al. Cigarette-smoke-induced oxidative/nitrosative stress impairs VEGF- and fluidshear-stress-mediated signaling in endothelial cells. Antioxid Redox Signal 2010; 12 : 1355-1369.

30. Chen HW, Lii CK, Ku HJ, Wang TS. Cigarette smoke extract induces expression of cell adhesion molecules in HUVEC via actin filament reorganization. Environ Mol Mutagen 2009; 50: 96-104.

31. Messner B, Knoflach M, Seubert A, Ritsch A, Pfaller K, Henderson B et al. Cadmium is a novel and independent risk factor for early atherosclerosis mechanisms and in vivo relevance. Arterioscler Thromb Vasc Biol 2009; 29: 1392-1398.

32. Guarino F, Cantarella G, Caruso M, Russo C, Mancuso S, Arcidiacono G et al. Endothelia activation and injury by cigarette smoke exposure. J Biol Regul Homeost Agents 2011; 25: 259-268.

33. Csordas A, Kreutmayer S, Ploner C, Braun PR, Karlas A, Backovic A et al. Cigarette smoke extract induces prolonged endoplasmic reticulum stress and autophagic cell death in human umbilical vein endothelial cells. Cardiovasc Res 2011; 92: 141-148.

34. Penn A, Keller K, Snyder C, Nadas A, Chen LC. The tar fraction of cigarette smoke does not promote arteriosclerotic plaque development. Environ Health Perspect 1996; 104 $1108-1113$

35. Jianlin L, Guohai C, Guojun Z, Jian J, Fangfang H, Juanjuan X et al. Assessing cytogenotoxicity of cigarette smoke condensates using three in vitro assays. Mutat Res 2009; 677: 21-26.

36. Nordskog BK, Fields WR, Hellmann GM. Kinetic analysis of cytokine response to cigarette smoke condensate by human endothelial and monocytic cells. Toxicology 2005; 212 : 87-97.

37. Nordskog BK, Blixt AD, Morgan WT, Fields WR, Hellmann GM. Matrix-degrading and proinflammatory changes in human vascular endothelial cells exposed to cigarette smoke condensate. Cardiovasc Toxicol 2003; 3: 101-117.

38. Kalra VK, Ying Y, Deemer K, Natarajan R, Nadler JL, Coates TD. Mechanism of cigarette smoke condensate induced adhesion of human monocytes to cultured endothelial cells. J Cell Physiol 1994; 160: 154-162.

39. Shen Y, Rattan V, Sultana C, Kalra VK. Cigarette smoke condensate-induced adhesion molecule expression and transendothelial migration of monocytes. Am J Physiol 1996; 270(5 Part 2): H1624-H1633.

40. Snajdar RM, Busuttil SJ, Averbook A, Graham DJ. Inhibition of endothelial cell migration by cigarette smoke condensate. J Surg Res 2001; 96: 10-16.

41. Csordas A, Wick G, Bernhard D. Hydrogen peroxide-mediated necrosis induction in HUVECs is associated with an atypical pattern of caspase-3 cleavage. Exp Cell Res 2006; 312: $1753-1764$

42. DeMarini DM. Genotoxicity of tobacco smoke and tobacco smoke condensate: a review. Mutat Res 2004; 567: 447-474.

43. Eguchi Y, Shimizu S, Tsujimoto Y. Intracellular ATP levels determine cell death fate by apoptosis or necrosis. Cancer Res 1997; 57: 1835-1840.

44. Porter AG, Janicke RU. Emerging roles of caspase-3 in apoptosis. Cell Death Differ 1999; 6: 99-104.

45. Hampton MB, Orrenius S. Redox regulation of apoptotic cell death in the immune system. Toxicol Lett 1998; 102-103: 355-358.

46. Riedl SJ, Salvesen GS. The apoptosome: signalling platform of cell death. Nat Rev Mol Cell Biol 2007: 8: 405-413.

47. Daugas E, Susin SA, Zamzami N, Ferri KF, Irinopoulou T, Larochette $\mathrm{N}$ et al. Mitochondrio-nuclear translocation of AIF in apoptosis and necrosis. FASEB J 2000; 14 729-739.

48. Joza N, Susin SA, Daugas E, Stanford WL, Cho SK, Li CY et al. Essential role of the mitochondrial apoptosis-inducing factor in programmed cell death. Nature 2001; 410: 549-554.

49. Turk B, Turk V. Lysosomes as 'suicide bags' in cell death: myth or reality? J Biol Chem 2009; 284: 21783-21787.

50. Guicciardi ME, Leist M, Gores GJ. Lysosomes in cell death. Oncogene 2004; 23 : 2881-2890.

51. Pratt MM, John K, MacLean AB, Afework S, Phillips DH, Poirier MC. Polycyclic aromatic hydrocarbon (PAH) exposure and DNA adduct semi-quantitation in archived human tissues. Int J Environ Res Public Health 2011; 8: 2675-2691.

52. Calafat AM, Polzin GM, Saylor J, Richter P, Ashley DL, Watson CH. Determination of tar, nicotine, and carbon monoxide yields in the mainstream smoke of selected international cigarettes. Tob Control 2004; 13: 45-51.

53. Amberger A, Maczek C, Jurgens G, Michaelis D, Schett G, Trieb K et al. Co-expression of ICAM-1, VCAM-1, ELAM-1 and Hsp60 in human arterial and venous endothelial cells in response to cytokines and oxidized low-density lipoproteins. Cell Stress Chaperones 1997; 2: 94-103.

54. Bernhard D, Huck CW, Jakschitz T, Pfister G, Henderson B, Bonn GK et al. Development and evaluation of an in vitro model for the analysis of cigarette smoke effects on cultured cells and tissues. J Pharmacol Toxicol Methods 2004; 50: 45-51.

55. Sigl R, Wandke C, Rauch V, Kirk J, Hunt T, Geley S. Loss of the mammalian APC/C activator FZR1 shortens $\mathrm{G} 1$ and lengthens $S$ phase but has little effect on exit from mitosis. J Cell Sci 2009; 122(Part 22): 4208-4217. 
60. Messner B, Zeller I, Ploner C, Frotschnig S, Ringer T, Steinacher-Nigisch A et al. Ursolic acid causes DNA-damage, p53-mediated, mitochondria- and caspase-dependent human endothelial cell apoptosis, and accelerates atherosclerotic plaque formation in vivo. Atherosclerosis 2011; 219: 402-408.

57. Ploner C, Rainer J, Niederegger H, Eduardoff M, Villunger A, Geley S et al. The BCL2 rheostat in glucocorticoid-induced apoptosis of acute lymphoblastic leukemia. Leukemia 2008; 22: 370-377

58. Bernhard D, Pfister G, Huck CW, Kind M, Salvenmoser W, Bonn GK et al. Disruption of vascular endothelial homeostasis by tobacco smoke: impact on atherosclerosis. FASEB J 2003; 17: 2302-2304

59. Bernhard D, Skvortsov S, Tinhofer I, Hubl H, Greil R, Csordas A et al. Inhibition of histone deacetylase activity enhances Fas receptor-mediated apoptosis in leukemic lymphoblasts. Cell Death Differ 2001; 8: 1014-1021.

(c) Cell Death and Disease is an open-access journal published by Nature Publishing Group. This work is licensed under the Creative Commons Attribution-NonCommercial-No Derivative Works 3.0 Unported License. To view a copy of this license, visit http://creativecommons.org/licenses/by-nc-nd/3.0/

Supplementary Information accompanies the paper on Cell Death and Disease website (http://www.nature.com/cddis) 